\title{
Erratum to: Antifilarial activity of diterpenoids from Taxodium distichum
}

\author{
Vikas Kushwaha ${ }^{1 \dagger}$, Kirti Saxena ${ }^{1 \dagger}$, Richa Verma', Shiv K. Verma ${ }^{1,4}$, Deepali Katoch², Neeraj Kumar ${ }^{2}$, Brij Lal ${ }^{3}$, \\ P. Kalpana Murthy ${ }^{1^{*}}$ and Bikram Singh ${ }^{2^{*}}$
}

\section{Erratum}

In the paper [1] the present address of the Corresponding Author 'P. Kalpana Murthy' should read as:

CSIR Emeritus Scientist, Department of Zoology, Lucknow University, University Road, Lucknow 226007, India.

The following information is added in the Acknowledgements' section:

"Thanks are due to CSIR, New Delhi, for award of Emeritus Scientist Project to PKM. Thanks are also due to Vice Chancellor, Lucknow University, Lucknow, for providing laboratory space and computational facilities to PKM for carrying out part of the study, data analysis and manuscript preparation."

\begin{abstract}
Author details
'Division of Parasitology, CSIR-Central Drug Research Institute, New Campus, BS 10/1, Sector 10, Jankipuram Extension, Lucknow 226 031, India. ${ }^{2}$ Natural Product Chemistry and Process Development Division, CSIR-Institute of Himalayan Bioresource Technology, Palampur 176 061, HP, India. ${ }^{3}$ Biodiversity Division, CSIR-Institute of Himalayan Bioresource Technology, Palampur 176 061, HP, India. ${ }^{4}$ Present Address: USDA, ARS, APDL, BARC-East Bldg 1001, 10300 Baltimore Avenue, Beltsville, MD 20705, USA.
\end{abstract}

Received: 28 March 2017 Accepted: 28 March 2017

Published online: 26 April 2017

\section{Reference}

1. Kushwaha V, Saxena K, Verma R, Verma SK, Katoch D, Kumar N, et al.

Antifilarial activity of diterpenoids from Taxodium distichum. Parasit Vectors. 2016;9:312.

\footnotetext{
*Correspondence: drpkmurthy@yahoo.com; drpkmurthy@gmail.com; psr_murthy@yahoo.com; bikramsingh@ihbt.res.in;

bikram_npp@rediffmail.com

${ }^{\dagger}$ Equal contributors

'Division of Parasitology, CSIR-Central Drug Research Institute, New Campus, BS 10/1, Sector 10, Jankipuram Extension, Lucknow 226 031, India

${ }^{2}$ Natural Product Chemistry and Process Development Division, CSIR-Institute of Himalayan Bioresource Technology, Palampur 176 061, HP, India Full list of author information is available at the end of the article
} 